\title{
JAK-inhibitor and type I interferon ability to produce favorable clinical outcomes in COVID-19 patients: a systematic review and meta-analysis
}

Lucas Walz ${ }^{1,2}$, Avi J. Cohen ${ }^{2}$, Andre P. Rebaza ${ }^{3}$, James Vanchieri ${ }^{2}$, Martin D. Slade ${ }^{4}$, Charles S. Dela Cruz ${ }^{2,5^{*+}}$ and Lokesh Sharma ${ }^{2^{*}+}$

\begin{abstract}
Background: The spread of a highly pathogenic, novel coronavirus (SARS-CoV-2) has emerged as a once-in-acentury pandemic, having already infected over 63 million people worldwide. Novel therapies are urgently needed. Janus kinase-inhibitors and Type I interferons have emerged as potential antiviral candidates for COVID-19 patients due to their proven efficacy against diseases with excessive cytokine release and their direct antiviral ability against viruses including coronaviruses, respectively.

Methods: A search of MEDLINE and MedRxiv was conducted by three investigators from inception until July 30th 2020 and included any study type that compared treatment outcomes of humans treated with Janus kinaseinhibitor or Type I interferon against controls. Inclusion necessitated data with clearly indicated risk estimates or those that permitted their back-calculation. Outcomes were synthesized using RevMan.

Results: Of 733 searched studies, we included four randomized and eleven non-randomized trials. Five of the studies were unpublished. Those who received Janus kinase-inhibitor had significantly reduced odds of mortality $(\mathrm{OR}, 0.12 ; 95 \% \mathrm{Cl}, 0.03-0.39, p<0.001)$ and ICU admission (OR, 0.05; 95\% Cl, 0.01-0.26, $\mathrm{p}<0.001)$, and had significantly increased odds of hospital discharge (OR, 22.76; $95 \% \mathrm{Cl}, 10.68-48.54, p<0.00001)$ when compared to standard treatment group. Type I interferon recipients had significantly reduced odds of mortality $(O R, 0.19 ; 95 \% \mathrm{Cl}$, $0.04-0.85, p<0.05)$, and increased odds of discharge bordering significance $(\mathrm{OR}, 1.89 ; 95 \% \mathrm{Cl}, 1.00-3.59, p=0.05)$.

Conclusions: Janus kinase-inhibitor treatment is significantly associated with positive clinical outcomes in terms of mortality, ICU admission, and discharge. Type I interferon treatment is associated with positive clinical outcomes in regard to mortality and discharge. While these data show promise, additional well-conducted RCTs are needed to further elucidate the relationship between clinical outcomes and Janus kinase-inhibitors and Type I interferons in COVID-19 patients.
\end{abstract}

Keywords: Viral infection, Respiratory infection, Infection control

\footnotetext{
*Correspondence: charles.delacruz@yale.edu; lokeshkumar.sharma@yale.edu

${ }^{\dagger}$ Charles S. Dela Cruz and Lokesh Sharma are contributed equally as senior authors.

${ }^{2}$ Section of Pulmonary and Critical Care and Sleep Medicine, Department of Internal Medicine, Yale University School of Medicine, S440, 300 Cedar Street, New Haven, CT 06520, USA

Full list of author information is available at the end of the article
}

C C The Author(s). 2021 Open Access This article is licensed under a Creative Commons Attribution 4.0 International License, which permits use, sharing, adaptation, distribution and reproduction in any medium or format, as long as you give appropriate credit to the original author(s) and the source, provide a link to the Creative Commons licence, and indicate if changes were made. The images or other third party material in this article are included in the article's Creative Commons licence, unless indicated otherwise in a credit line to the material. If material is not included in the article's Creative Commons licence and your intended use is not permitted by statutory regulation or exceeds the permitted use, you will need to obtain permission directly from the copyright holder. To view a copy of this licence, visit http://creativecommons.org/licenses/by/4.0/ The Creative Commons Public Domain Dedication waiver (http://creativecommons.org/publicdomain/zero/1.0/) applies to the data made available in this article, unless otherwise stated in a credit line to the data. 


\section{Background}

The spread of a highly pathogenic novel coronavirus (SARS-CoV-2) has emerged as the deadliest pandemic since influenza in 1918, posing significant challenges for public health organizations, health care providers, and governments at all levels [1]. Severe disease caused by SARS-CoV-2 (COVID-19) has strained resources critical for patient care as well as those needed for protection of healthcare professionals such as personal protective equipment (PPE) around the world [2]. This, combined with limited therapeutic options, have led to Intensive Care Unit (ICU) mortality rates as high as $20 \%$ in some population subsets [3]. As of December 1st, SARS-CoV2 has infected over 63 million people worldwide and led to the death of over 1.4 million patients [4]. Currently, only a few therapeutic approaches have been suggested to improve disease outcomes in susceptible populations, with only a few large-scale randomized clinical trials (RCTs) or observational studies having been conducted so far. These studies demonstrated modest effectiveness for agents such as remdesivir or dexamethasone [5, 6]. Additional therapeutics against COVID-19 are being explored, but in absence of large-scale RCTs, it remains difficult to assess the effectiveness of many of these therapies.

Janus-kinases (JAKs) are transmembrane proteins that mediate and amplify extracellular signals from growth factors and cytokines. Their inhibitors have been found to be effective in treating patients with inflammatory diseases [7]. These inhibitors function by targeting specific JAKs. Both Baricitinib and Ruxolitinib predominantly inhibit JAK1 and JAK2 [7]. JAK-inhibitors may be used to control high levels of cytokines and inflammation [8], as seen in patients with severe SARS-CoV-2 infection [9]. These inhibitors have proved helpful in "off-label" indications, where excessive cytokine release plays a central role in disease progression [10]. While the hypothesis of JAK-inhibitors successfully combating high levels of cytokine expression in SARS-CoV-2 infection has been reinforced in some small studies [11], their effect on a larger population has not been investigated.

Interferons, including Type I interferons (interferon- $\alpha$ / $\beta$ ) and Type III interferons $(\lambda)$, are proteins secreted by infected cells that induce antiviral states in neighboring cells and stimulate cytokine production [12]. These interferons work through activation of JAK/STAT pathway to activate a multitude of genes that are collectively known as interferon-stimulated genes (ISGs). These ISGs act together to block the viral life cycle at different stages. Given the widespread expression of Type I interferon receptors, they function as broad-spectrum antivirals that can directly and indirectly inhibit the replication of by promoting the expression of ISGs [13]. These interferons have been found to have positive therapeutic effects in the treatment of viral infections including hepatitis [14], and coronaviruses such as SARS and MERS $[15,16]$. One investigation assessed Type I recombinant interferon to be one of the most potent anti-SARS-CoV-2 antiviral agents [17]. Additionally, a recent investigation revealed that several severe cases of COVID-19 presented with a rare, X-chromosome lossof-function mutation that impaired Type I interferon response [18], while another demonstrated an association between COVID-19 severity and Type I interferon deficiency [19]. Other studies have also implicated low levels of Type I and III interferons as partially responsible for the unique and inappropriate inflammatory response seen in COVID-19 patients [20]. Various studies have found reasons to support the use of Type I interferons in combination with other antivirals to promote positive outcomes among patients with COVID-19, but many are restricted by the limited number of patients treated with interferon [21]. Interestingly, these interferons perform their functions by activating the JAK pathway.

Uncertainty and a lack of clinically proven prophylactic and therapeutic options have precipitated the periodic update of treatment guidelines for patients infected with COVID-19. As such, systematic reviews evaluating effects in larger patient populations are necessary to ascertain drug-related COVID-19 outcomes. In this metaanalysis, we evaluate JAK-inhibitors and Type I interferons for their efficacy and ability to produce positive outcomes in patients infected with SARS-CoV-2.

\section{Methods}

This systematic review was conducted in accordance with Preferred Reporting Items for Systematic Reviews and Meta-Analyses (PRISMA; Supplementary Table 5) [22].

\section{Search strategy and study quality assessment}

MEDLINE (via PubMed) and MedRxiv were searched since inception throughout July 30th, 2020 by three investigators ( $\mathrm{LW}, \mathrm{AC}, \mathrm{JV})$. The following terms were searched in free-text fields for JAK-inhibitors. For MEDLINE: "COVID-19" AND "JAK inhibitor" OR "Ruxolitinib” OR “Tofacitinib” OR "Fedratinib” OR "Baricitinib" OR "Pacritinib". For MedRxiv: "COVID-19 JAK inhibitor" OR "COVID-19 Ruxolitinib" OR "COVID-19 Tofacitinib" OR "COVID-19 Fedratinib” OR "COVID-19 Baricitinib" OR “COVID-19 Pacritinib”. The following terms were searched in free-text fields for Type I interferons. For MEDLINE: “COVID-19"[Title] AND “interferon"[Title/Abstract] OR "IFN"[Title/Abstract]. For MedRxiv: "COVID-19 interferon" or "COVID-19 IFN".

Three investigators (LW, AJC, JV) independently screened titles and abstracts generated by the search. After selection, full electronic articles were then carefully evaluated for data extraction. Randomized studies 
included in the final analyses were scored by one investigator (LW) to formally assess for risk of bias utilizing the Risk of Bias (RoB) 2 tool (Supplementary Table 3) [23]. Non-randomized studies included in the final analyses were scored by one investigator (LW), utilizing the Newcastle-Ottawa Scale (NOS) according to the following study characteristics: (1) representativeness of exposed cohort, (2) selection of nonexposed cohort, (3) exposure assessment, (4) outcome of interest not present at the start of the study, (5) comparability of cohorts, (6) outcome assessment, (7) adequacy of length of time before follow-up, and (8) adequacy of follow-up of cohorts (Supplementary Table 4) [24].

\section{Inclusion and exclusion criteria}

We included clinical trials that utilized combination or sole JAK-inhibitor or Type I interferon (IFN- $\alpha$, IFN- $\beta$ ) for the treatment of confirmed COVID-19 infection. For inclusion, possible studies must have compared treatment outcomes of those treated with a JAK-inhibitor or Type I interferon against a defined control group that did not receive this treatment. Selection required data with clearly indicated risk ratios or odds ratios (OR), or those that permitted their back-calculation. Inclusion necessitated that the trial be a human study accessible in English, and could include pediatric or adult studies, observational studies, retrospective cohorts, randomized clinical trials, and case reports.
Studies that utilized in vivo or animal studies, as well as those examining histological, pathological, and cellular mechanisms were excluded. Duplicate studies, review articles, commentaries, and proposed protocols were also excluded. Trials were excluded if they primarily examined other therapies where outcomes were unclear as to which participants received JAK-inhibitors or Type I interferons. Finally, studies were not included if they presented outcomes considered heterogeneous across the review that made statistical synthesis impossible (e.g. Mean vs Median).

\section{Data extraction and data analysis}

Each full article that met inclusion criteria was carefully reviewed with the following baseline information extracted: first author, publication year, country, study type, type of JAK-inhibitor or interferon used, number of total participants, number of participants receiving JAK-inhibitor or interferon, and outcome measurements (Table 1). The outcome measurements consolidated included mortality, disease severity (mild/moderate vs severe/critical), mechanical ventilation, ICU admission, discharge, and acute respiratory distress syndrome (Supplementary Table 1). Additional individual study definitions of COVID-19 disease severity are presented in Supplementary Table 2.

ORs were extracted from articles or calculated from the presented data. Data were analyzed using Review

Table 1 Baseline characteristics of included studies. Included studies classifications of First Author, Year, Country, Study Type, Type of JAK-inhibitor/Type I interferon Used, Total Number of Participants, Number of Participants Receiving JAK-inhibitor/Type I interferon Used. Studies presented in alphabetical order by treatment group

\begin{tabular}{llllll}
\hline First Author, Year & Country & Study Type & $\begin{array}{l}\text { JAK-inhibitor/ } \\
\text { Interferon Used }\end{array}$ & $\begin{array}{l}\text { Total \# of } \\
\text { Participants }\end{array}$ & $\begin{array}{l}\text { N Participants Receiving } \\
\text { JAK-inhibitor/Interferon }\end{array}$ \\
\hline Bronte 2020 [25] & Italy & Observational & Baricitinib & 76 & 20 \\
Cantini 2020a [26] & Italy & Retrospective Cohort & Baricitinib & 191 & 113 \\
Cantini 2020b [27] & Italy & Prospective Cohort, open-label & Baricitinib & 24 & 12 \\
Cao 2020 [28] & China & RCT & Ruxolitinib & 41 & 20 \\
Giudice 2020 [29] & Italy & RCT & Ruxolitinib & 17 & 7 \\
Chen 2020 [30] & China & Observational & IFN-alpha-2b & 291 & 132 \\
Davoudi-Monfared 2020 [31] & Iran & RCT & IFN-beta-1a & 81 & 42 \\
Du 2020 [32] & China & Retrospective Cohort & IFN-alpha & 182 & 178 \\
Estébanez 2020 [33] & Spain & Retrospective Cohort & IFN-beta-1b & 256 & 106 \\
Fan 2020 [34] & China & Retrospective Observational & IFN-alpha-1b & 53 & 19 \\
Hung 2020 [35] & China & RCT & IFN-beta-1b & 127 \\
Liu 2020 [36] & China & Retrospective Observational & IFN-alpha-2b & 10 & 86 \\
Pereda 2020 [37] & Cuba & Retrospective Cohort & IFN-alpha-2b & 814 \\
Wang 2020 [38] & China & Retrospective Cohort & IFN-alpha-2b & 446 \\
Zhou 2020 [39] & China & Retrospective Cohort & IFN & 221 & 246 \\
\hline
\end{tabular}

IFN Interferon

${ }^{\text {a }}$ No Study participants received JAK-inhibitor and Type I interferon

${ }^{b}$ Unclear - Used in combination with Arbidol 
Manager version 5.4 (Cochrane Corporation, Oxford, United Kingdom) and the Mantel-Haenszel method. All analyzed variables are dichotomous. Thus, crude ORs and 95\% confidence intervals (CIs) are reported. Heterogeneity was assessed using tau-squared and chi-squared tests for random effects and fixed effect models, respectively, as well as the $\mathrm{I}^{2}$ statistic. For $\mathrm{I}^{2}>50 \%$, the random effects model was used. Otherwise, the fixed effects model was utilized. An alpha of 0.05 was adopted to determine significance.

\section{Results}

The initial database search returned 731 articles. Two additional articles were added by manually searching retrieved reviews. After removing two duplicates, 698 articles were excluded following title and abstract screening by three investigators. After comprehensive evaluation of 33 full-text articles, only 15 studies complied with the inclusion criteria. The majority of the studies excluded in the final step were excluded on the basis of not presenting outcome data in terms of those who did and did not receive JAK-inhibitor or interferon treatment. The remainder were excluded due to a focus on JAK inhibition as prophylaxis, a focus on interferon therapy as prophylaxis, or heterogeneity in reporting time among outcomes that precluded calculating pooled measures. Of the included studies, five were pre-prints. Overall, the 15 studies were comprised of four observational studies, six retrospective cohorts, four RCTs, and one prospective cohort. Figure 1 presents the meta-analysis flow chart and Table 1 presents the designs and characteristics of the included studies.

While some studies did not report which drugs were given as standard of care, many others reported treating patients with glucocorticoids, hydroxychloroquine, chloroquine, arbidol, and lopinavir/ritonavir. All studies were conducted within a hospital setting.

\section{Effect of JAK inhibition on clinical outcomes in COVID-19}

A total of five studies investigated the effect of JAK inhibition in a controlled setting (Table 1), enrolling a total of 172 patients who received a JAK-inhibitor and 177 control participants [25-29]. The common parameters that were measured included mortality, ICU

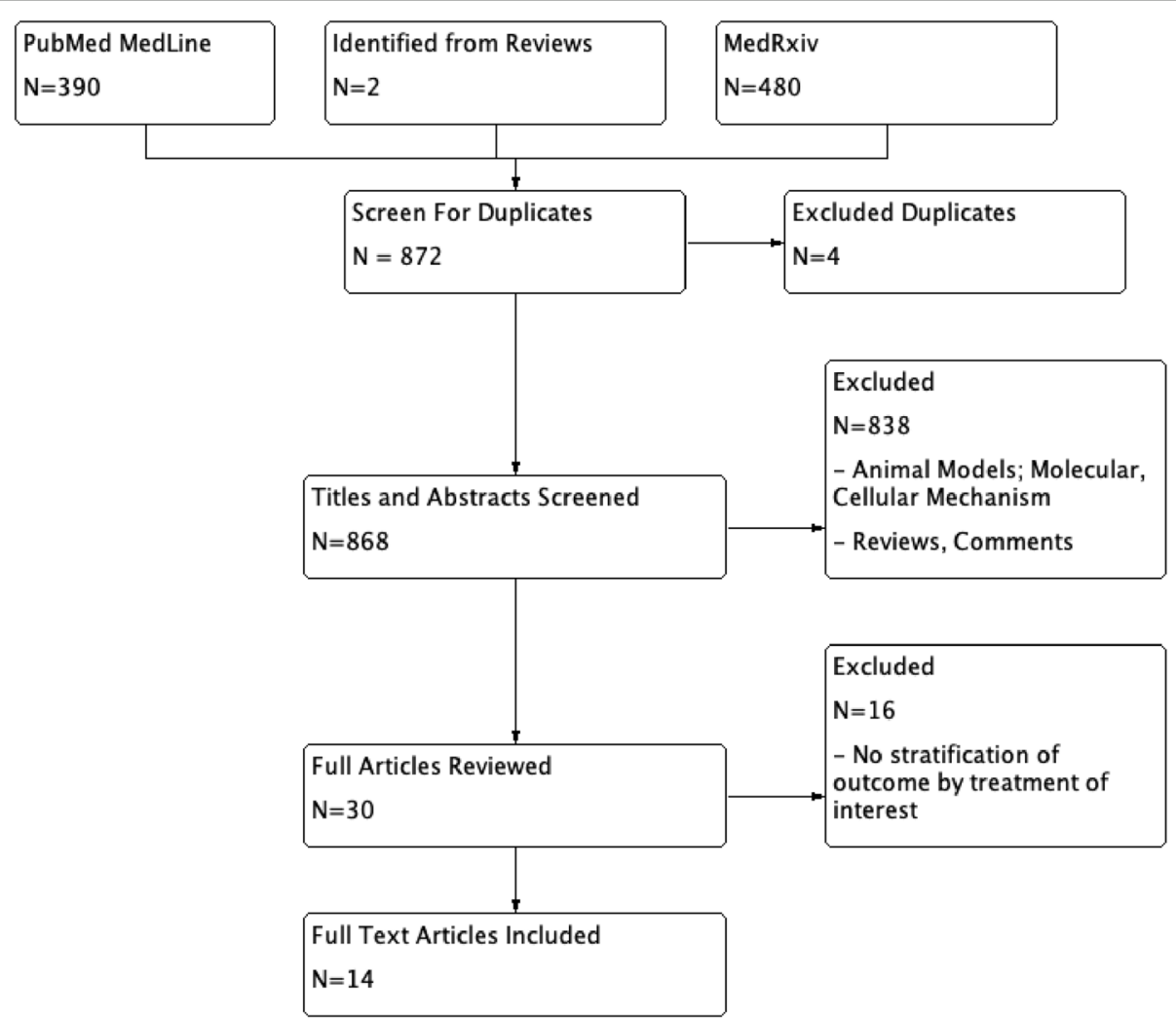

Fig. 1 Flow diagram of study identification and assessment for eligibility. Two hundred twenty seven and 504 studied were identified from the databases Medline and MedRxIV, respectively. Two additional articles were added by manually searching retrieved reviews. Two articles were removed as duplicates. Six hundred ninety eight were removed after title and abstract screening not meeting inclusion criteria. Eighteen articles were removed after evaluation of the full article, with 15 included articles remaining 
A. Mortality

Odds Ratio

Odds Ratio

Study or Subgroup

Weight $\mathrm{M}-\mathrm{H}$, Fixed, $95 \% \mathrm{Cl}$

Bronte 2020

54.3\% $0.07[0.01,0.52]$

Cantinl 2020a

$28.1 \% 0.06[0.00,1.08]$

Cantinl 2020b

Not estimable

Cao 2020

$14.5 \% \quad 0.13[0.01,2.67]$

Gludice 2020

$3.1 \times 1.50[0.08,28.89]$

Total $(95 \% \mathrm{Cl})$

$100.0 \%$

$0.12[0.03,0.39]$

Total events

Heterogenely: $\mathrm{Ch}^{2}=3.38$, df $=3(\mathrm{P}=0.34) ; \mathrm{r}^{2}=11 \mathrm{x}$

Test for overall effect: $Z=3.47$ (P $=0.0005)$

M-H, Fixed, 95\% Cl

B. ICU Admission

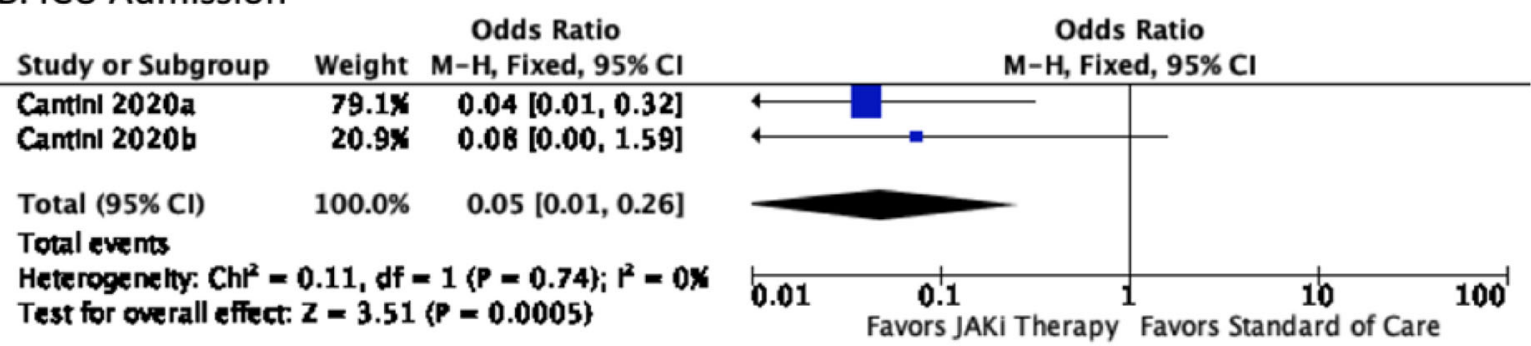

C. Mechanical Ventilation

Odds Ratio

Odds Ratio

Study or Subgroup Weight $\mathrm{M}-\mathrm{H}$, Fixed, $95 \% \mathrm{Cl}$

$\begin{array}{llr}\text { Can 2020 } & 73.8 \% & 0.13[0.01,2.67] \\ \text { Gludke 2020 } & 26.2 \% & 0.42[0.01,11.92]\end{array}$

Total $(95 \% \mathrm{Cl})$

$100.0 \%$

$0.21[0.02,1.85]$

Total events

Heterogenelty: $\mathrm{Ch}^{2}=0.27$, df $=1\left\langle(P=0.60) ; \mathrm{r}^{2}=0 \mathrm{X}\right.$

Test for overall effect: $Z=1.41(P=0.16)$

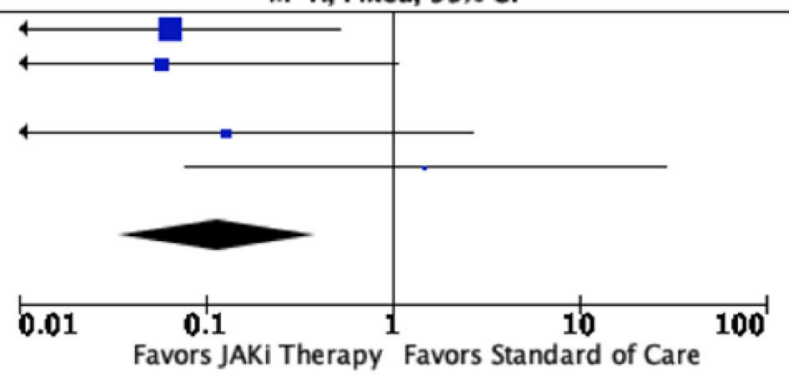

D. Acute Respiratory Distress Syndrome (ARDS)|

$$
\text { Odds Ratio }
$$

Study or Subgroup Weight $\mathrm{M}-\mathrm{H}$, Fixed, $95 \% \mathrm{CI}$

$\begin{array}{lll}\text { Bronte } 2020 & 70.4 \% & 0.4 B\end{array}[0.12,1.8 B]$

Gludke $2020 \quad 29.6 \% \quad 0.25[0.02,2.94]$

Total $(95 \% \mathrm{Cl}) \quad 100.0 \% \quad 0.41[0.13,1.36]$

Total events

Heterogenelty: $\mathrm{Ch}^{2}=0.21$, df $=1(P=0.65) ; \mathrm{P}^{2}=0 \mathrm{X}$

Test for overall effect: $Z=1.45$ (P $=0.15$ \}

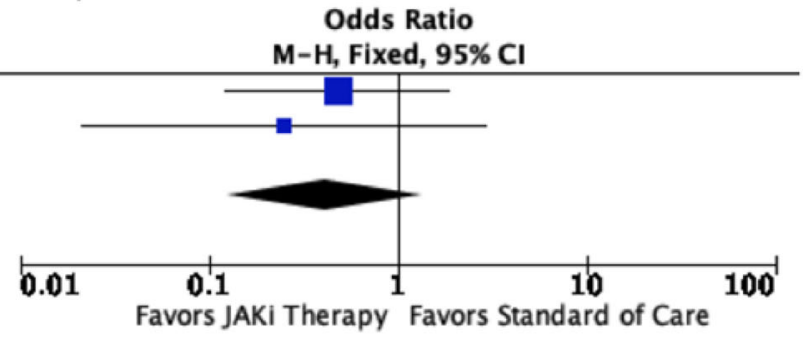

E. Discharge

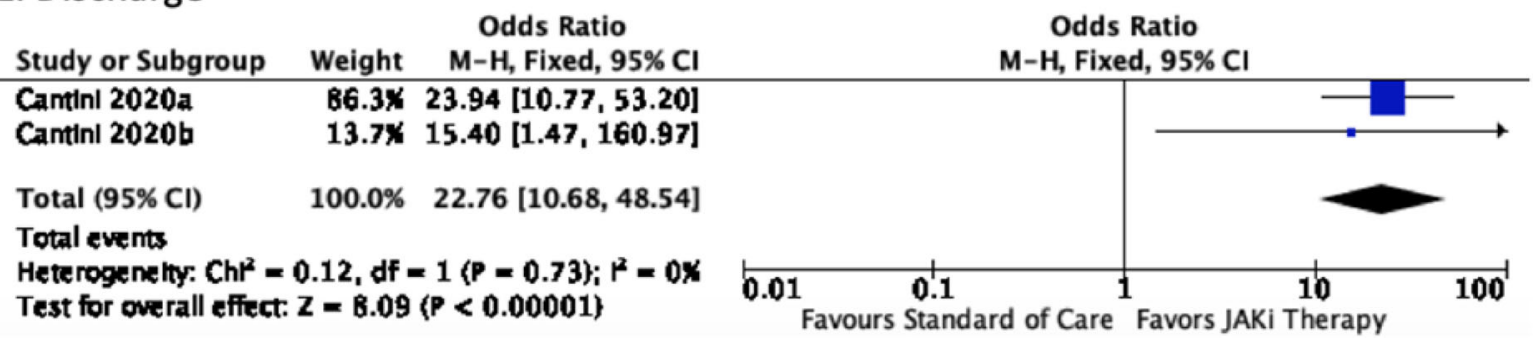

Fig. 2 (See legend on next page.) 
(See figure on previous page.)

Fig. 2 Forest plot of (a) Mortality, (b) ICU Admission, (c) Requirement of Mechanical Ventilation, (d) ARDS, and (e) Discharge of patients treated with JAK-inhibitor. The fixed effects model was used. JAK-inhibitor treatment group saw significantly reduced odds of mortality and ICU admission, as well as significantly higher odds of discharge, when compared to standard treatment. There was no significant difference between groups in regards to requiring mechanical ventilation, or the development of ARDS. The meta-analysis results are presented on forest plots, with a study's calculated OR plotted as a black square whose size is proportional to the weight afforded to the study. Bidirectional bars stemming from these black squares correspond to the risk estimate's 95\% Cl. Diamonds were used to represent the summary OR; its center aligns with the OR and its width represents the summary $95 \% \mathrm{Cl}$

admission, requiring mechanical ventilation, incidence of acute respiratory distress syndrome (ARDS), and 14-day discharge. Meta-analysis of the five studies revealed a significantly lower odds of mortality with JAK-inhibitor (OR, 0.12; 95\% CI, 0.03-0.39; $p=0.0005$ ), as compared to standard treatment. The effect size among the different studies demonstrated relatively little heterogeneity $\left(\mathrm{I}^{2}=\right.$ $11 \%$; Fig. 2a). Pooled analyses of 2 sets of studies revealed that there was no significant association between JAK-inhibitor and COVID-19 patients requiring mechanical ventilation or developing ARDS, respectively ( $p>$ 0.05; Fig. 2c and d). Both analyses included 27 patients receiving a JAK inhibitor, while the mechanical ventilation and ARDS analyses included 31 and 66 control patients, respectively. Investigation of 125 JAK-inhibitor and 90 control COVID-19 patients found that those treated with JAK-inhibitor, in comparison to those receiving standard treatment, demonstrated 0.05 (95\% CI, 0.01-0.26) times the odds of being admitted into the ICU ( $p=0.0005$; Fig. 2b). Finally, analysis of 2 studies of 215 patients, 125 of which were treated with a JAKinhibitor, revealed that those treated with JAK-inhibitor had significantly higher odds than those treated with standard care to be discharged at 2 weeks (OR, 22.76; 95\% CI, 10.68-48.54; $p<0.00001$; Fig. 2e). The analysis examining the relationship between treatment with JAKinhibition and requiring mechanical ventilation, developing ARDS, ICU admittance, and hospital discharge demonstrated very little heterogeneity $\left(\mathrm{I}^{2}=0\right)$.

\section{Effect of interferon therapy on clinical outcomes in COVID-19}

Meta-analysis of 3 sets of studies with 990, 454, and 1480 patients receiving Type I interferon therapy revealed that there were no significant associations between receiving Type I interferon therapy and ICU admittance, requiring mechanical ventilation, or developing a severe or critical case of COVID-19 ( $p>0.05$; Fig. 3b, c, d) compared to the control arm [30-32, 3439]. The analyses included 97,167 , and 537 control patients, respectively. The data exhibited very high heterogeneity in cases of ICU admittance and disease severity (both $\mathrm{I}^{2}>90 \%$ ), but relatively low in the case of mechanical ventilation $\left(\mathrm{I}^{2}=12 \%\right)$. In the analyses of the 803 and 1415 Type I interferon receiving patients, intervention therapy was respectively associated with higher odds of being discharged (OR, 1.89; 95\% CI, 1.00-3.59; $p=0.05$; $N=895$; Fig. 3e), and significantly lower odds of mortality (OR, 0.19; 95\% CI, 0.04-0.85); $p=0.03, N=1906$; Fig. 3a), when compared to standard of care. The studies included in these analyses enlisted 92 and 491 control patients, respectively. Discharge data exhibited very low heterogeneity $\left(\mathrm{I}^{2}=0 \%\right)$, while mortality data demonstrated very high heterogeneity $\left(\mathrm{I}^{2}=90 \%\right)$.

\section{Discussion}

As SARS-CoV-2 continues to infect millions and kill thousands daily, there is an urgent need to find novel therapies that can effectively limit COVID-19 severity. Type I interferon therapy and JAK-inhibitors represent paradoxical approaches to treat COVID-19. While Type I interferon therapy aims to limit the viral replication at the early time points to limit the subsequent disease, JAK-inhibitors aim to limit the overt inflammation that may be detrimental to the host and cause systemic inflammatory response. However, no major randomized clinical trials have been performed to determine their efficacy in limiting the disease severity in COVID-19. Many randomized clinical trials examining the effect of JAK-inhibitors or Type I Interferon therapy for treatment of COVID-19 patients are underway [40, 41].

To our knowledge, this is the first systematic review and meta-analysis to investigate the role of JAKinhibitors or Type I interferons on clinical outcomes in patients with COVID-19. The results suggest a robust association between JAK-inhibitor and significantly decreased odds of mortality and ICU admission, as well as significantly increased odds for patient discharge within 2 weeks. Furthermore, a significant association between Type I interferon and reduced mortality was also found, in addition to an association with hospital discharge that bordered significance. These results suggest the potential benefit of these therapeutic options for COVID-19.

Although this study presents evidence of JAKinhibitors and Type I interferon therapies for COVID-19 patients, the evaluated studies included conflicting results: Giudice et al. reported a positive association between JAK-inhibitor therapy and the odds of mortality [29], while the other studies analyzed demonstrated a negative association between JAK-inhibitor intervention 
A. Mortality

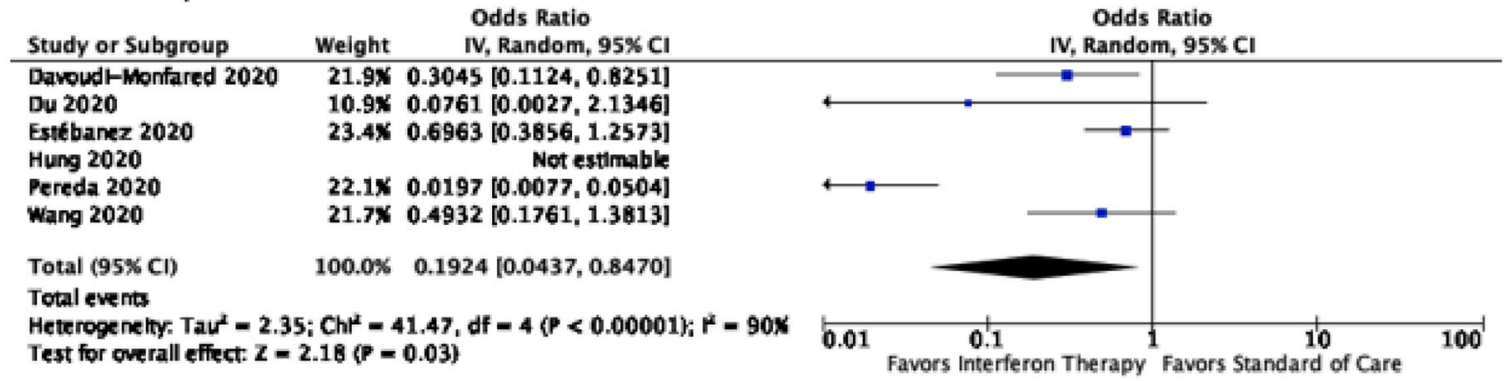

B. ICU Admission

\begin{tabular}{|c|c|c|}
\hline study of subgroup & Weight & $\mathrm{M}-\mathrm{H}$, Random, $95 \% \mathrm{c}$ \\
\hline Davoud-Monfarę 2020 & $29.3 \mathrm{~K}$ & $0.72[0.30,1.7$ \\
\hline Du 2020 & $21.3 x$ & $0.18[0.01,4.0$ \\
\hline Uu 2020 & $19.9 x$ & $1.62[0.05,51.1$ \\
\hline Pereda 2020 & $29.6 x$ & $0.02[0.01,0.0$ \\
\hline Total $(95 \% \mathrm{Cl})$ & $100.0 \%$ & $0.21[0.02,2$ \\
\hline
\end{tabular}

Total events

Hetterogenelty: Taur $=5.95 ; \mathrm{ChH}^{2}=45.52$, df $=3(\mathrm{P}<0.00001)_{\mathrm{i}} \mathrm{H}^{\mathrm{a}}=93 \mathrm{x}$

Test for overall effect: $Z=1.15(\mathrm{P}=0.25)$

Odds Ratio

$\mathrm{M}-\mathrm{H}$, Random, $95 \% \mathrm{Cl}$

C. Mechanical Ventilation

Odds Ratio

Weight $\mathrm{M}=\mathrm{H}$, Fixed, $95 \% \mathrm{Cl}$

Study or Subgroup

Davoud-Monfared 2020

$63.6 \mathrm{X}$

$5.3 \%$

Du 2020

Hung 2020

บu 2020

$11.3 \%$

$0.72[0.29,1.76]$

$0.18[0.01,4.01]$

$0.16[0.01,3.92]$

Not estimable

Zhou 2020

$19.6 \%$

$1.82[0.4 B, 6.94]$

Total $(95 \% \mathrm{Cl})$

$100.0 \%$

$0.85[0.43,1.67]$

Total eve nts

Heterogenelty: $\mathrm{ChP}^{3}=3.41, \mathrm{df}=3(\mathrm{P}=0.33) ; \mathrm{P}^{*}=12 \mathrm{X}$

Test for overall effect: $\mathrm{Z}=0.4 \mathrm{~B}$ ( $\mathrm{P}=0.63$ )

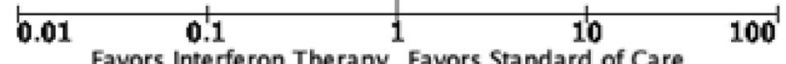

Favors Interferon Therapy Favors Standard of Care

\section{Disease Severity}

Study or Subgroup Weight M-H, Random, $95 \% \mathrm{Cl}$

Chen $2020 \quad 16.5 \mathrm{X} \quad 0.56[0.30,1.07]$

Du $2020 \quad 10.5 \%$

Fan $2020 \quad 14.2 \% \quad 0.55[0.10,3.04]$

$9.6 \mathrm{x}$

$3.67[0.12,113.73]$

Pereda $2020 \quad 16.4 X \quad 0.02[0.01,0.04]$

Wang $2020 \quad 16.7 x \quad 1.70[1.09,2.65]$

Zhou 2020

$3.34[1.32,8.43]$

Total $(95 \% \mathrm{CD} \quad 100.0 \% \quad 0.56[0.11,2.85]$

Total events

Heterogenelty: Taut $=4.06 ; \mathrm{Ch}^{2}=130.14$, df $=6(P<0.00001) ; \mathrm{P}^{\mathrm{A}}=95 \mathrm{~K}$

Test for overall effect: $Z=0.70(P=0.49$ )

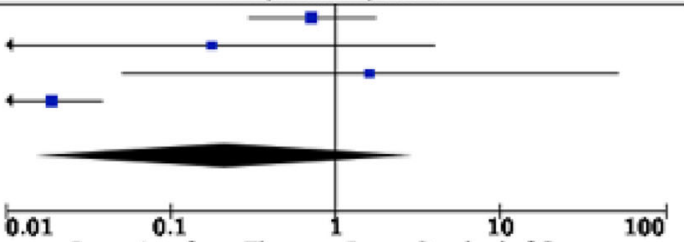

Favors Interferon Therapy Favors standard of Care

Odds Ratio

$\mathrm{M}=\mathrm{H}$, Fixed, $95 \% \mathrm{Cl}$

\section{E. Discharge}

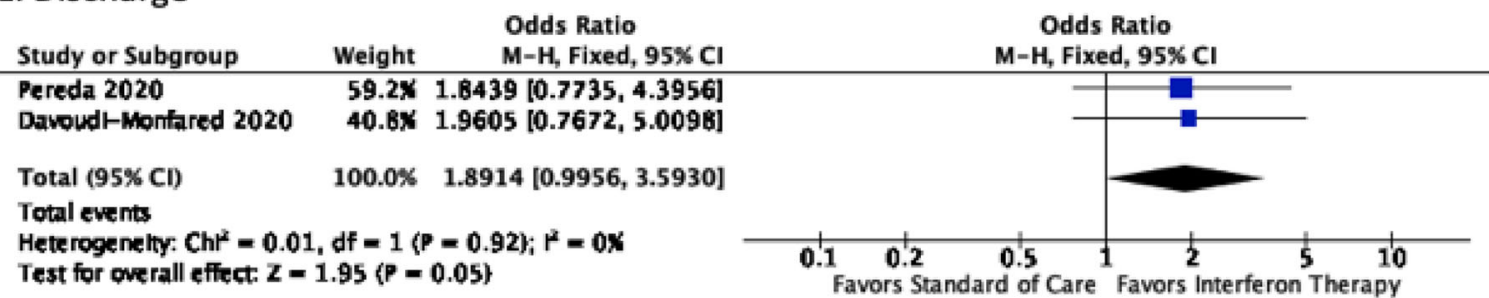

Fig. 3 (See legend on next page.) 
(See figure on previous page.)

Fig. 3 Forest plot of (a) Mortality, (b) ICU Admission, (c) Requirement of Mechanical Ventilation, (d) Severe or Critical Disease, and (e) Discharge of patients treated with Type I interferon. The fixed effects and random effects model was used dependent on the $I^{2}$ measure of heterogeneity. Type I interferon group saw significantly reduced odds of mortality, as well as increased odds of discharge that bordered significance, when compared to standard treatment. There was no significant difference between groups in regards to requiring ICU admission, mechanical ventilation, or the development of severe or critical disease. The meta-analysis results are presented on forest plots, with a study's calculated OR plotted as a black square whose size is proportional to the weight afforded to the study. Bidirectional bars stemming from these black squares correspond to the risk estimate's $95 \% \mathrm{Cl}$. Diamonds were used to represent the summary OR; its center aligns with the OR and its width represents the summary $95 \% \mathrm{Cl}$

and mortality [25, 26, 28]. In addition, two studies consistently demonstrated opposite associations between Type I interferon therapy and clinical outcomes [36, 39], compared to other included studies [30-32, 34, 37]. Heterogeneity among study populations may play a role in the disparate results, as half of these studies were conducted in China, one in Iran, five in Western Europe, and one in Cuba. Other irreconcilable factors that may have influenced patient outcomes included individual study exclusion criterion, as well as the dosage and delivery method of the intervention.

Furthermore, as recent findings have shown that persistent viral presence contributes to disease severity [42], the timing of the administration of both interventions may be of utmost importance. As JAK-inhibitors attenuate JAK signaling and subsequent cytokine release, their administration may best be suited for patients with progressing COVID-19 who have not yet experienced a cytokine storm [43]. By contrast, as Type I interferons induce cellular antiviral states via the JAK/STAT pathway, its administration may be most efficacious early on in disease where the virus is still replicating. While the literature surrounding this is sparse, one study included in this meta-analysis concluded that early administration of interferon-alpha- $2 \mathrm{~b}$ could induce positive outcomes in COVID-19 patients compared to standard treatment, while its late administration was associated with slower recovery [38].

It is important to highlight that this meta-analysis attempted to overcome the challenges posed by studies with insufficient power to detect an effect between JAKinhibitor or Type I interferon treatment and clinical outcomes, as half of the included studies in this analysis utilized sample sizes less than 100 [25, 27-29, 31, 34, 36]. Nevertheless, despite the broad range of sample sizes and populations, the screening step of our analysis predominantly resulted in low effect size heterogeneity as evidenced by the $\mathrm{I}^{2}$ statistics displayed in Fig. 2 and Fig. 3.

This study contained no restrictions regarding study type in the exclusion criteria and, as such, many of the studies included are of retrospective design. Accordingly, baseline characteristics of patients cannot be ignored, especially as factors such as age, gender, and pre-existing comorbidities have been found in meta-analyses to be linked to negative clinical outcomes, including mortality, among COVID-19 patients [44]. One study in particular contained a large disparity in the distribution of chronic conditions across those who received Type I interferon therapy and controls [37]. Furthermore, this meta-analysis included two studies consisting of similar study teams that examined the same association [26, 27], enhancing the likelihood of bias in the same direction in analyses where both of these studies were included.

In addition to heterogeneous outcome reporting, the small sample sizes in peer-reviewed literature would not have provided enough statistical power for meta-analysis if not for the inclusion of articles in pre-print. The inclusion of pre-published work in meta-analyses has long been debated but are currently of utmost importance to push for larger randomized clinical trials during this critical time. Their inclusion may help attenuate artificially extreme effect estimates and counteract publication bias, but may leave the study vulnerable to further bias and misrepresentation $[45,46]$. For that reason, all included studies, published and pre-published, were individually reviewed in the evaluation of bias according to randomization status. Risk-of-bias assessments are presents in Supplementary Table 3 and Supplementary Table 4.

\section{Conclusions}

This meta-analysis supports the value of JAK-inhibitors and Type I interferon therapy in combating SARS-CoV2 infection. This study consolidates existing data and reaffirms the conclusion that, within COVID-19 patients, JAK-inhibitor treatment is significantly associated with positive clinical outcomes in terms of mortality, ICU admission, and discharge, as well as Type I interferon treatment's association with positive clinical outcomes in regard to mortality and discharge. Although these findings should assist physicians in deciding which antivirals to administer to SARS-CoV-2 infected patients, they also point to a clear need for additional well-designed RCTs examining the relationship of JAK-inhibitors and Type I interferon and clinical outcomes of COVID-19 patients.

\section{Supplementary Information}

The online version contains supplementary material available at https://doi. org/10.1186/s12879-020-05730-z. 
Additional file 1: Supplementary Figures. Supplementary Figure 1. Funnel plots of JAK-inhibitor treatment for (A) Mortality, (B) ICU Admission, (C) Requirement of Mechanical Ventilation, (D) ARDS, and (E) Discharge.

Supplementary Figure 2. Funnel plots of Type I interferon treatment for (A) Mortality, (B) ICU Admission, (C) Requirement of Mechanical Ventilation, (D) Severe or Critical Disease, and (E) Discharge. Supplementary Table 1. Total outcome data stratified by included study. Supplementary Table 2 . Definition of a severe or critical case in included studies for which that measure was analyzed. Supplementary Table 3. Risk of Bias (RoB) 2 check list for detection of bias in randomized trials. Supplementary Table 4. Newcastle-Ottowa Scale (NOS) tool for risk of bias detection in nonrandomized trials. Supplementary Table 5. PRISMA-P 2015 checklist: recommended items to address in a systematic review protocol.

\section{Acknowledgments}

Not applicable.

\section{Authors' contributions}

LW; conception of investigation, planning of investigation, data retrieval, article screening, data analysis, written reporting, data interpretation. AJC; planning of investigation, data retrieval, article screening, data analysis, written reporting, data interpretation. APR; written reporting, data interpretation. JV: data retrieval, article screening. MDS: data analysis. CSDC: planning of investigation, data retrieval, written reporting, data interpretation; supervision. LS: conception of investigation, planning of investigation, written reporting, data interpretation; supervision. The authors read and approved the final manuscript.

\section{Funding}

Lokesh Sharma is supported by Parker B Francis Fellowship and American Lung Association Catalyst Award. Charles Dela Cruz is supported by Veterans Affairs Merit Grant (BX004661), Department of Defense grant (PR181442), and a U19 supplement for this work (Al089992-09S2).

\section{Availability of data and materials}

The datasets used and analyzed during the current study are available from the corresponding author on reasonable request.

\section{Ethics approval and consent to participate}

Not applicable.

\section{Consent for publication}

Not applicable.

\section{Competing interests}

The authors declare that they have no competing interests.

\section{Author details}

'Department of Epidemiology of Microbial Diseases, Yale School of Public Health, New Haven, CT 06520, USA. ${ }^{2}$ Section of Pulmonary and Critical Care and Sleep Medicine, Department of Internal Medicine, Yale University School of Medicine, S440, 300 Cedar Street, New Haven, CT 06520, USA. ${ }^{3}$ Section of Pediatric Pulmonary, Allergy, Immunology and Sleep Medicine, Department of Pediatrics, Yale School of Medicine, New Haven, CT 06520, USA. ${ }^{4}$ Department of Internal Medicine, Yale School of Medicine, New Haven, CT 06520, USA. ${ }^{5}$ Department of Microbial Pathogenesis, Yale School of Medicine, New Haven, CT 06520, USA.

Received: 7 September 2020 Accepted: 21 December 2020 Published online: 11 January 2021

\section{References}

1. Gates B. Responding to Covid-19 - a once-in-a-century pandemic? N Engl J Med. 2020;382(18):1677-9.

2. Emanuel EJ, Persad G, Upshur R, et al. Fair allocation of scarce medical resources in the time of Covid-19. N Engl J Med. 2020;382(21):2049-55.

3. Goyal P, Choi JJ, Pinheiro LC, et al. Clinical characteristics of Covid-19 in New York City. N Engl J Med. 2020;382(24):2372-4.
4. Center JHUoMCR. COVID-19 dashboard by the Center for Systems Science and Engineering (CSSE) at Johns Hopkins University (JHU); 2020. Available from: https://coronavirus.jhu.edu/map.html.

5. Beigel JH, Tomashek KM, Dodd LE, et al. Remdesivir for the treatment of Covid-19 — preliminary report. N Engl J Med. 2020;383:992-4.

6. RECOVERY Collaborative Group. Horby P, Lim WS, Emberson JR. Dexamethasone in Hospitalized Patients with Covid-19 - Preliminary Report. N Engl J Med. 2020. https://doi.org/10.1056/NEJMoa2021436.

7. Bertsias $\mathrm{G}$. Therapeutic targeting of JAKs: from hematology to rheumatology and from the first to the second generation of JAK inhibitors. Mediterr J Rheumatol. 2020;31(Suppl 1):105-11 PubMed PMID: PMC7361188. eng.

8. Gaspari V, Zengarini C, Greco S, Vangeli V, Mastroianni A. Side effects of ruxolitinib in patients with SARS-CoV-2 infection: Two case reports. Int J Antimicrob Agents. 2020;56(2):106023. https://doi.org/10.1016/j.ijantimicag. 2020.106023 .

9. Portsmore S, Tran Nguyen TN, Beacham E, et al. Combined IL-6 and JAKSTAT inhibition therapy in COVID-19 related SHLH, potential game changer. Br J Haematol. 2020. https://doi.org/10.1111/bjh.16966 PubMed PMID: 32584421. eng.

10. La Rosée F, Bremer HC, Gehrke I, et al. The Janus kinase 1/2 inhibitor ruxolitinib in COVID-19 with severe systemic hyperinflammation. Leukemia. 2020;34(7):1805-15.

11. Zhang $X$, Zhang $Y$, Qiao $W$, et al. Baricitinib, a drug with potential effect to prevent SARS-COV-2 from entering target cells and control cytokine storm induced by COVID-19. Int Immunopharmacol. 2020;86:106749 PubMed PMID: PMC7328558. Epub 2020/07/01. eng.

12. Ivashkiv LB, Donlin LT. Regulation of type I interferon responses. Nat Rev Immunol. 2014;14(1):36-49 PubMed PMID: 24362405. eng.

13. Wang BX, Fish EN. Global virus outbreaks: Interferons as 1st responders. Semin Immunol. 2019;43:101300 PubMed PMID: 31771760. eng.

14. Cornberg M, Wedemeyer H, Manns MP. Hepatitis C: therapeutic perspectives. Forum (Genova). 2001;11(2):154-62 PubMed PMID: 11948360. eng.

15. Loutfy MR, Blatt LM, Siminovitch KA, et al. Interferon Alfacon-1 plus corticosteroids in severe acute respiratory SyndromeA preliminary study. JAMA. 2003;290(24):3222-8.

16. Chan JFW, Chan K-H, Kao RYT, et al. Broad-spectrum antivirals for the emerging Middle East respiratory syndrome coronavirus. J Inf Secur. 2013; 67(6):606-16 PubMed PMID: 24096239. Epub 2013/10/03. eng.

17. Yuan S, Chan CC, Chik KK, et al. Broad-Spectrum host-based antivirals targeting the interferon and Lipogenesis pathways as potential treatment options for the pandemic coronavirus disease 2019 (COVID19). Viruses. 2020;12(6):628Published 2020 Jun 10. https://doi.org/10. 3390/v12060628.

18. van der Made Cl, Simons A, Schuurs-Hoeijmakers J, et al. Presence of genetic variants among young men with severe COVID-19. JAMA. 2020; 324(7):663-73. https://doi.org/10.1001/jama.2020.13719.

19. Hadjadj J, Yatim N, Barnabei L, et al. Impaired type I interferon activity and inflammatory responses in severe COVID-19 patients. Science. 2020; 369(6504):718-24. https://doi.org/10.1126/science.abc6027. Epub 2020 Jul 13. PMID: 32661059; PMCID: PMC7402632.

20. Blanco-Melo D, Nilsson-Payant BE, Liu WC, et al. Imbalanced host response to SARS-CoV-2 drives development of COVID-19. Cell. 2020;181(5):10361045.e9. https://doi.org/10.1016/j.cell.2020.04.026.

21. Dastan F, Nadji SA, Saffaei A, et al. Subcutaneous administration of interferon beta-1a for COVID-19: a non-controlled prospective trial. Int Immunopharmacol. 2020;85:106688 PubMed PMID: 32544867. Epub 2020/ 06/07. eng.

22. Liberati A, Altman DG, Tetzlaff J, et al. The PRISMA statement for reporting systematic reviews and meta-analyses of studies that evaluate healthcare interventions: explanation and elaboration. BMJ. 2009;339: b2700.

23. Sterne JAC, Savović J, Page MJ, et al. RoB 2: a revised tool for assessing risk of bias in randomised trials. BMJ. 2019;366:14898.

24. Cook DA, Reed DA. Appraising the quality of medical education research methods: the medical education research study quality instrument and the Newcastle-Ottawa scale-education. Acad Med. 2015;90(8):1067-76 PubMed PMID: 00001888-201508000-00023.

25. Bronte V, Ugel S, Tinazzi E, Vella A, De Sanctis F, Canè S, et al. Baricitinib restrains the immune dysregulation in severe COVID-19 patients. J Clin Invest. https://doi.org/10.1172/JCl141772. 
26. Cantini F, Niccoli L, Nannini C, et al. Beneficial impact of Baricitinib in COVID-19 moderate pneumonia; multicentre study. J Infect. 2020;81(4):64779. https://doi.org/10.1016/j.jinf.2020.06.052.

27. Cantini F, Niccoli L, Matarrese D, et al. Baricitinib therapy in COVID-19: a pilot study on safety and clinical impact. J Inf Secur. 2020:S01634453(20)30228-0 PubMed PMID: 32333918. eng.

28. Cao Y, Wei J, Zou L, et al. Ruxolitinib in treatment of severe coronavirus disease 2019 (COVID-19): a multicenter, single-blind, randomized controlled trial. J Allergy Clin Immunol. 2020;146(1):137-46.e3 PubMed PMID: 32470486. Epub 2020/05/26. eng.

29. Giudice V, Pagliano P, Vatrella A, et al. Combination of Ruxolitinib and Eculizumab for treatment of severe SARS-CoV-2-related acute respiratory distress syndrome: a controlled study. Front Pharmacol. 2020;11:857 PubMed PMID: 32581810. eng.

30. Chen X, Zheng F, Qing Y, et al. Epidemiological and clinical features of 29 cases with coronavirus disease 2019 in areas adjacent to Hubei, China: a double-center observational study. medRxiv. 2020. https://doi.org/10.1101/ 2020.03.03.20030353.

31. Davoudi-Monfared $\mathrm{E}$, Rahmani $\mathrm{H}$, Khalili $\mathrm{H}$, et al. Efficacy and safety of interferon $\beta$-1a in treatment of severe COVID-19: a randomized clinical trial. Antimicrob Agents Chemother. 2020:AAC.01061-20.

32. Du, H, Dong, X, Zhang, J-J, et al. Clinical characteristics of 182 pediatric COVID-19 patients with different severities and allergic status. Allergy. 2020; 00:1-23. https://doi.org/10.1111/all.14452.

33. Estebanez M, Ramirez-Olivencia G, Mata T, et al. Clinical evaluation of IFN beta1b in COVID-19 pneumonia: a retrospective study. medRxiv. 2020 https://doi.org/10.1101/2020.05.15.20084293.

34. Fan L, Liu C, Li N, et al. Medical treatment of 55 patients with COVID-19 from seven cities in Northeast China who fully recovered: a single-center, retrospective, observational study. medRxiv. 2020. https://doi.org/10.1101/ 2020.03.28.20045955.

35. Hung IF-N, Lung K-C, Tso EY-K, et al. Triple combination of interferon beta$1 \mathrm{~b}$, lopinavir-ritonavir, and ribavirin in the treatment of patients admitted to hospital with COVID-19: an open-label, randomised, phase 2 trial. Lancet 2020;395(10238):1695-704.

36. Liu F, Xu A, Zhang Y, et al. Patients of COVID-19 may benefit from sustained Lopinavir-combined regimen and the increase of eosinophil may predict the outcome of COVID-19 progression. Int J Infect Dis. 2020;95:183-91 PubMed PMID: 32173576. Epub 2020/03/12. eng.

37. Pereda R, Gonzalez D, Rivero H, et al. Therapeutic effectiveness of interferon-alpha2b against COVID-19: the Cuban experience. medRxiv. 2020. https://doi.org/10.1101/2020.05.29.20109199.

38. Wang N, Zhan Y, Zhu L, et al. Retrospective multicenter cohort study shows early interferon Therapy Is Associated with Favorable Clinical Responses in COVID-19 Patients. Cell Host Microbe. 2020;28(3):455-464.e2. https://doi.org/ 10.1016/j.chom.2020.07.005

39. Zhou Y, He X, Zhang J, Ye $X$, et al. Prolonged SARS-CoV-2 viral shedding in patients with COVID-19 was associated with delayed initiation of Arbidol treatment: a retrospective cohort study. medRxiv. 2020. https://doi.org/10. 1101/2020.06.09.20076646.

40. ClinicalTrials.gov [Internet]. National Library of Medicine (US). Bethesda (MD): Search Results; [Accessed 2020 August 23]. Available from: https:// clinicaltrials.gov/ct2/results?cond=Covid19\&term=Interferon\&cntry=\&state $=$ \&city $=\&$ dist $=$.

41. ClinicalTrials.gov [Internet]. National Library of Medicine (US). Bethesda (MD): Search Results; [Accessed 2020 August 23]. Available from: https:// clinicaltrials.gov/ct2/results?cond=COVID19\&term=Janus+kinase+ inhibitor\&cntry $=\&$ state $=\&$ city $=\&$ dist $=$.

42. Chang $D$, Zhao $P$, Zhang $D$, et al. Persistent viral presence determines the clinical course of the disease in COVID-19. J Allergy Clin Immunol Pract 2020;8(8):2585-91.e1. https://doi.org/10.1016/j.jaip.2020.06.015. Epub 2020 Jun 20. PMID: 32574840; PMCID: PMC7305869.

43. Wang J, Jiang $M$, Chen $X$, et al. Cytokine storm and leukocyte changes in mild versus severe SARS-CoV-2 infection: review of 3939 COVID-19 patients in China and emerging pathogenesis and therapy concepts. J Leukoc Biol. 2020;108(1):17-41 PubMed PMID: 32534467. Epub 2020/06/13. eng.

44. Lu L, Zhong W, Bian Z, et al. A comparison of mortality-related risk factors of COVID-19, SARS, and MERS: A systematic review and metaanalysis. J Infect. 2020;81(4):e18-25. https://doi.org/10.1016/j.jinf.2020.07. 002.
45. Halfpenny NJA, Quigley JM, Thompson JC, Scott DA. Value and usability of unpublished data sources for systematic reviews and network metaanalyses. Evid Based Med. 2016;21(6):208-13.

46. Cook DJ, Guyatt GH, Ryan G, Clifton J, Buckingham L, Willan A, et al. Should unpublished data be included in meta-analyses?: current convictions and controversies. JAMA. 1993;269(21):2749-53.

\section{Publisher's Note}

Springer Nature remains neutral with regard to jurisdictional claims in published maps and institutional affiliations.

\section{Ready to submit your research? Choose BMC and benefit from:}

- fast, convenient online submission

- thorough peer review by experienced researchers in your field

- rapid publication on acceptance

- support for research data, including large and complex data types

- gold Open Access which fosters wider collaboration and increased citations

- maximum visibility for your research: over $100 \mathrm{M}$ website views per year

At $\mathrm{BMC}$, research is always in progress.

Learn more biomedcentral.com/submissions 